\title{
Knowledge, perceptions and practices of menstrual hygiene among degree college students in Guntur city of Andhra Pradesh, India
}

\author{
Christina Patricia Balla ${ }^{1 *}$, Samson Sanjeeva Rao Nallapu ${ }^{2}$
}

\begin{abstract}
${ }^{1}$ Department of Obstetrics and Gynecology, Katuri Medical College, Guntur District, Andhra Pradesh, India
${ }^{2}$ Department of Community Medicine, NRI Medical College, Guntur District, Andhra Pradesh, India
\end{abstract}

Received: 30 July 2018

Accepted: 29 August 2018

\author{
*Correspondence: \\ Dr. Christina Patricia Balla, \\ E-mail: patriciasamson@yahoo.com
}

Copyright: (c) the author(s), publisher and licensee Medip Academy. This is an open-access article distributed under the terms of the Creative Commons Attribution Non-Commercial License, which permits unrestricted non-commercial use, distribution, and reproduction in any medium, provided the original work is properly cited.

\begin{abstract}
Background: The unmet menstrual hygiene needs of young girls in India restrict their mobility and daily activities. Taboos and socio-cultural restrictions contribute to poor knowledge and practices leading to adverse health outcomes. This study is set to look at the knowledge, perceptions and practices concerning menstruation among college going girls.

Methods: This study was conducted with 254-degree college students from a women's degree college in Guntur city. After assuring adequate confidentiality, a self-administered questionnaire was administered to each participant. The information obtained was entered and analysed in MS excel. Important findings were subjected to statistical tests like Chi square and $\mathrm{Z}$ test for significance testing at $5 \%$ LOS.

Results: Mother's education was significantly related to the girls' knowledge about menses ( $\square 2$ 16.6, p 0.00002). A positive perception of menses was associated with good knowledge about it. $(\mathrm{p}<0.00001)$. Complaints related to menses were also associated with good knowledge scores ( $\square 2$ 9.8, p 0.002). Absenteeism during periods was 81.5\%, the causes being pain $60.4 \%$, heavy bleeding $31.4 \%$, both pain and heavy bleeding $4.8 \%$ and nausea $3.4 \%$.

Conclusions: The associated symptoms of menstruation need to be addressed in schools and colleges and in their respective homes. Ensuring availability of sanitary products, water, privacy and appropriate waste disposal in all public services and institutions can address the challenges.
\end{abstract}

Keywords: Knowledge, Menstruation, Menstrual hygiene, Perceptions, Sanitary materials

\section{INTRODUCTION}

Menstruation, a very important everyday challenge for women in India, is however enveloped in silence and secrecy leading to socio cultural, economic and technical boundaries which limit their empowerment. Restrictions are placed on women and girls during menstruation and they are excluded from various activities. Many young girls and women suffer from health problems associated with menstruation. Many women also lack the facilities and resources they need for menstrual hygiene. ${ }^{1}$ The practical (water, sanitation, hygiene and health related needs) and psychological aspects of menstruation inversely creates a sense of insecurity in young girls both in urban and rural environments in India. ${ }^{2}$ The unmet menstrual hygiene needs restrict their mobility and also daily activities including education. Taboos and sociocultural boundaries surrounding menstruation contribute to their poor knowledge concerning the scientific facts and hygienic health practices regarding it leading to adverse health outcomes. ${ }^{3}$

Many young girls are uninformed and unprepared for menarche. Mothers, other female family members and female teachers, who are the primary source of information, may not be equipped to provide necessary 
knowledge. Exclusion and shame lead to misconceptions and unhygienic practices during menstruation. Rather than seek medical consultation, girls tend to miss school, self-medicate and refrain from social interaction. Relatives and teachers are often not prepared to respond to their needs. ${ }^{4}$

Privacy is also an issue for young girls regarding their menstruation and menstrual hygiene practice. In the limited shared spaces in an average Indian home, ensuring adequate privacy for a young girl to wash, change, dry and dispose whatever menstrual method she uses is essential. ${ }^{5}$ Anand $\mathrm{E}$ et al state that various studies show that both Reproductive tract infections (RTI) and Vaginal discharge are related with non-use of hygienic methods during menstruation. ${ }^{6}$

According to the National Family Health Survey (NFHS) 4 (2015 -16), only $57.6 \%$ of women (Urban 77.5, Rural 48.2 ) in the age group of 15 to 24 years use hygienic methods of protection during their menstrual period. Sanitary napkins, tampons and locally prepared napkins are considered as hygienic methods of protection. ${ }^{7}$ To facilitate better menstrual hygiene among college going girls in India, there is a need not only for improvement in knowledge and practices, but also access to materials like sanitary pads, clean toilets with running water and most importantly, privacy. A favorable social and physical environment along with individual knowledge is the need of the hour. Social restrictions in many communities include not entering the prayer room, and not entering the kitchen during menstruation. Such limitations do have an impact on the emotional state, mindset and lifestyle of young girls and women. It is of concern that a large number of girls in less economically developed countries drop out of school at menarche. ${ }^{8}$

Studies indicate that close to $50 \%$ of Indian girls have no knowledge of menstruation prior to their first period and nearly $88 \%$ girls and women who menstruate use unsafe materials. There is considerable doubt whether used sanitary materials come under biomedical or plastic waste, thereby making its safe disposal a problem. Menstrual health and hygiene is part of the National Health Mission, the flagship programme of the Government of India launched in 2005. The primary focus has been on raising awareness on menstrual hygiene.

Most policy initiatives addressing Menstrual Hygiene Management (MHM) are centered on adolescent girls. The focus is primarily on the hardware (i.e. infrastructure, sanitary napkins) or software (i.e. health education) components.

Programmes suggest convergence with other government programmes, yet operationalisation of convergence mechanisms is lacking. ${ }^{9}$ The key reasons for menstrual hygiene include promotion of healthy sexual maturation and prevention of diseases. Learning about the menstrual cycle is important for adolescents and young girls for the purpose of knowing about fertile periods and of contraception. Sufficient know-ledge of menstruation will empower them to distinguish between normal and abnormal uterine bleeding. ${ }^{10}$ Positive perceptions and behaviours regarding menstruation and menstrual practices will disperse fears, anxiety and other problems that young girls encounter at this special period of need and support. ${ }^{11}$ This study is set to look at the knowledge, attitude and practices regarding menstruation among college going girls in Guntur city of Andhra Pradesh.

\section{METHODS}

This study was conducted with 254-degree college (BSc, B Com and BA) students from a local private women's degree college in Guntur city during the months of February and March 2018. After assuring adequate confidentiality and obtaining informed consent, a predesigned, pretested, structured, self-administered questionnaire was administered to each participant. The questionnaire contained in addition to various demographic details, items on awareness of menarche before the start of menstruation, of the awareness; knowledge of source of bleeding, perception of menstruation as a normal phenomenon, information sources for menstruation, type of absorbent used, disposal of absorbents, daily bathing, restrictions imposed, school absenteeism during menstruation, change of absorbent in school and availability of toilets at home etc. The information obtained was entered in MS excel and analysed for percentages and presented in the form of tables and graphs. Important findings were subjected to statistical tests like Chi square and $\mathrm{Z}$ test for significance testing at $5 \%$ LOS.

\section{RESULTS}

The average age of the participants is 19.2 years (SD 0.92). Of them $84.3 \%$ are Hindus, $9.4 \%$ Christian and the rest $6.3 \%$ Muslims. $85 \%$ of their fathers are selfemployed in various businesses including farming sector (11.0\% in private service and only $3.9 \%$ in Govt service). $48.4 \%$ of fathers had only primary education as also $58.3 \%$ of the mothers. $93.7 \%$ of the mothers of the participants are housewives. $61.0 \%$ belong to nuclear type of family while $28.7 \%$ are extended and only $10.2 \%$ from a joint family. Monthly average family income is around twenty thousand rupees. Sanitation wise, $85 \%$ of the families had a shared toilet, $14.2 \%$ of the girls had an individual toilet. Only 2 girls $(0.8 \%)$ had no toilet. Sufficient water was available to $95.3 \%$ of the girls ( $69.7 \%$ continuous and $25.6 \%$ stored) and only $4.7 \%$ had poor water supply. On an average the girls in the study had their menarche at age 13 years. Most of the girls $(52 \%)$ said that they had no source of information about menstruation. An important source is an elderly relative $(36.6 \%)$. Information from health personnel is only $2.4 \%$. Some amount of knowledge about menstruation before menarche was seen only in $37.4 \%$ of the girls. 


\section{Knowledge about menstruation}

Adequate knowledge is seen regarding the usual number of the days of flow, age at menarche, duration of the cycle and change in pattern of menstrual cycle with changes in life style. More than half the girls have more than $50 \%$ of knowledge about menstruation. Only $4.7 \%$ of the girls knew that menstrual bleeding comes from the uterus. They also understand that menstrual cycles make women capable of child bearing. Only $26.4 \%$ of the girls were fully aware of the fertile period (Table 1).

Table 1: Knowledge about menstruation among college girls in the study.

\begin{tabular}{|llll|}
\hline Questions & Correct answer & No. answered correctly & $\%$ \\
\hline Usual number of days of blood flow & 3 to 5 days & 222 & 87.4 \\
\hline Usual age at menarche & 12 to 15 years & 207 & 81.5 \\
\hline Change in routine work may cause change in menstrual cycle & True & 206 & 81.1 \\
\hline Normal menstrual cycle duration & 28 days & 197 & 77.6 \\
\hline Child bearing is possible only with menstrual cycles & True & 197 & 77.6 \\
\hline Girls reach puberty compared to boys & Before & 172 & 67.7 \\
\hline Initial menstrual cycles are longer & True & 159 & 62.6 \\
\hline Usual age at menopause & 45 to 52 years & 158 & 62.2 \\
\hline Before 17 years age sanitary pads are not needed & False & 131 & 51.6 \\
\hline At puberty change to body weight & Increases & 99 & 39.0 \\
\hline During menstruation, swimming and running are dangerous & False & 98 & 38.6 \\
\hline The fertile period is in which part of the cycle & Middle & 71 & 28.0 \\
\hline No. of fertile days in the menstrual cycle & Nine & 67 & 26.4 \\
\hline Menstruation clears dirty blood & False & 22 & 8.7 \\
\hline Organ from where blood comes & Uterus & 12 & 4.7 \\
\hline Girls are usually irritable during their periods & False & 4 & 1.6 \\
\hline
\end{tabular}

$59.8 \%$ of the girls said that they got their information from their mother, $11.4 \%$ from friends and only $9.1 \%$ from their teacher. When mothers were educated diploma and above, $85 \%$ of the girls had prior knowledge about menses (Chi square 16.6 Yates corrected, $\mathrm{p}$ value 0.00002). Taking a score of the key knowledge questions, we compared it to positive or negative perceptions about menstruation among the girls. It is seen that among the 180 girls who had a negative perception, $16.7 \%$ had good knowledge scores while among the 74 who had a positive perception, $80.1 \%$ had good knowledge scores. (p value < 0.00001 , OR 0.05 (95\% CI 0.02 to 0.10$)$. It shows that good knowledge about menses predisposes to a a very positive attitude towards it. Out of 104 girls with good knowledge scores only $16.3 \%$ had significant complaints related to menses, while among the 150 girls with poor knowledge scores, $34 \%$ had significant complaints (Chi sq 9.76, p 0.002 , OR $2.6495 \%$ CI 1.36 to 5.14 ).

\section{Common symptoms during menstruation}

Lower abdominal pain (68.9\%) and low backache $(78.3 \%)$ seem to be the most common physical complaints along with leg pains (59.1\%) during menstruation. Almost $50 \%$ of the girls have all three symptoms. A significant number of girls experience abdominal bloating, fatigue and frequent micturition. Headache and decreased appetite also seem to encumber the girls. Almost half of them feel sick and weak during menstruation. (Table 2)

Table 2: Common symptoms during menstruation among the college girls.

\begin{tabular}{|lll|}
\hline Symptom & Yes & $\%$ \\
\hline Low back pain & 199 & 78.3 \\
\hline Stabbing lower abdominal pain & 175 & 68.9 \\
\hline Stabbing leg pain & 150 & 59.1 \\
\hline Abdominal bloating & 125 & 49.2 \\
\hline Fatigue & 119 & 46.9 \\
\hline Frequent urge to pass urine & 82 & 32.3 \\
\hline Decreased appetite & 75 & 29.5 \\
\hline Headache & 59 & 23.2 \\
\hline Heavy bleeding & 61 & 24.0 \\
\hline Spotting before periods & 62 & 24.4 \\
\hline Passing clots & 98 & 38.6 \\
\hline
\end{tabular}

Most of the girls $(80.7 \%)$ said that they felt anxious about their periods and $41.3 \%$ said that they felt a sense of nervousness before the onset of menses. $48.0 \%$ said that they were unable to cope with menstruation and $49.2 \%$ also wished that they could disappear during periods.

However, a good percentage $(80.7 \%)$ said that they could talk to their family members about it and $84.3 \%$ of the 
girls said that they could talk to their friends about it (Table 3).

Table 3: Perceptions about menstruation.

\begin{tabular}{|lll|}
\hline Perceptions & No. & $\%$ \\
\hline Anxious about periods & 205 & 80.7 \\
\hline Nervous before periods & 105 & 41.3 \\
\hline Cannot cope & 122 & 48.0 \\
\hline Unable to talk to family members about it & 49 & 19.3 \\
\hline Unable to talk to friends about it & 40 & 15.7 \\
\hline Wishes to disappear during periods & 125 & 49.2 \\
\hline
\end{tabular}

Half of the girls experience moderate to severe pain and use drugs on their own for pain (Table 4).

Table 4: Symptomatic relief and consultation with medical professionals.

\begin{tabular}{|lll|}
\hline Pain due to menstruation & No. $(\mathrm{n}=254)$ & $\%$ \\
\hline Pain moderate to severe & 137 & 53.9 \\
\hline Drug use for pain & 94 & 37.0 \\
\hline Own analgesic use & 64 & 25.2 \\
\hline Relief - moderate to complete & 40 & 15.7 \\
\hline Consulted doctor for pain & 113 & 44.5 \\
\hline DGO & $23(\mathrm{n}=113)$ & 19.8 \\
\hline MBBS & $56(\mathrm{n}=113)$ & 48.3 \\
\hline Alternative Medicine & $16(\mathrm{n}=113)$ & 13.8 \\
\hline Quack & $18(\mathrm{n}=113)$ & 15.5 \\
\hline Diagnosis of PCOD & 61 & 24.0 \\
\hline
\end{tabular}

The other half usually consulted an MBBS doctor and sometimes a specialist and occasionally quacks. $24 \%$ of the girls who went to doctors were diagnosed to have Polycystic Ovarian Disease (PCOD). A significant number of girl's experience spotting before periods and also passage of blood clots.

\section{Materials used during menstruation}

It is essential that all the girls use sanitary pads during menstruation. In this study the average number of pads used per day during menses is around 3 (Table 5). About $27.2 \%$ use more than 3 pads. This corresponds to the number of girls complaining about excessive bleeding during menses i.e. $24.0 \%$. The study also revealed that $13.4 \%$ of the girls were using cloth and $6.3 \%$ were using both pads and cloth. Most of the students use only sanitary pads and are usually ready with pads in their bags.

Almost all the girls change their pads during college hours and also at night. A few girls use cloths along with sanitary pads and some only cloths. For most of the girl's privacy is not available and dress gets stained. It is good to know that there is adequate water available. It is disheartening to find out that one third of the girls are disposing pads in the toilet, the others in household waste and some by burning them.
Table 5: Sanitary Materials use during menstruation.

\begin{tabular}{|c|c|c|c|}
\hline & & $\begin{array}{l}\text { No. } \\
(n=254)\end{array}$ & $\%$ \\
\hline \multirow{4}{*}{$\begin{array}{l}\text { Type of } \\
\text { materials }\end{array}$} & Only Sanitary pads & 204 & 80.3 \\
\hline & Only cloth & 34 & 13.4 \\
\hline & $\begin{array}{l}\text { Sanitary pads and } \\
\text { cloth }\end{array}$ & 16 & 6.3 \\
\hline & $\begin{array}{l}\text { Ready with pads } \\
\text { in bag }\end{array}$ & 203 & 79.9 \\
\hline \multirow{4}{*}{$\begin{array}{l}\text { Number and } \\
\text { time of change }\end{array}$} & $\begin{array}{l}\text { Average no. of } \\
\text { pads used per day }\end{array}$ & 3 & \\
\hline & No. of pads $>3 /$ day & 69 & 27.2 \\
\hline & $\begin{array}{l}\text { Change pad during } \\
\text { college hours }\end{array}$ & 218 & 85.8 \\
\hline & $\begin{array}{l}\text { Change pad at } \\
\text { night }\end{array}$ & 243 & 95.7 \\
\hline \multirow{3}{*}{$\begin{array}{l}\text { Problems } \\
\text { associated }\end{array}$} & $\begin{array}{l}\text { No privacy } \\
\text { (secluded place) }\end{array}$ & 173 & 68.1 \\
\hline & Water shortage & 14 & 5.5 \\
\hline & Dress stained & 124 & 48.8 \\
\hline \multirow{3}{*}{ Disposal of pads } & $\begin{array}{l}\text { Disposal of pads } \\
\text { in toilet }\end{array}$ & 74 & 29.1 \\
\hline & $\begin{array}{l}\text { Disposal of pads } \\
\text { in household } \\
\text { wastes }\end{array}$ & 80 & 31.5 \\
\hline & $\begin{array}{l}\text { Disposal of pads } \\
\text { by burning }\end{array}$ & 100 & 39.4 \\
\hline
\end{tabular}

\section{Absence from college}

The current study revealed that $81.5 \%$ of the girls were absent one time or other from college due to menstruation related problems (pain $60.4 \%$, heavy bleeding $31.4 \%$, both pain and heavy bleeding $4.8 \%$ and nausea $3.4 \%$ ). $33.5 \%$ of them said that were regularly absent from college for more than 3 days during menstruation.

\section{Restrictions and false beliefs}

Most of the girls feel restricted during periods to attend places of worship, family functions and participating in sports and exercise.

Many of them avoid social activities and daily activities. Not much restriction is seen with activities with friends and school activities (Table 6).

Table 6: Restrictions during periods.

\begin{tabular}{|lll|}
\hline Restrictions & No. & $\%$ \\
\hline Family functions & 178 & 70.1 \\
\hline Places of worship & 163 & 64.2 \\
\hline Certain foods & 155 & 61.0 \\
\hline Sports and exercise & 140 & 55.1 \\
\hline Social activities & 97 & 38.2 \\
\hline Household kitchen & 90 & 35.4 \\
\hline School activities & 90 & 35.4 \\
\hline Activities with friends & 69 & 27.2 \\
\hline
\end{tabular}


98.4\% were convinced that girls are usually irritable during their periods. $91.3 \%$ of the girls are under the impression that menstruation clears the dirty blood from the body. $41.7 \%$ of the girls believed that menstruation is a divine gift to women. This is seen much more in the Muslim girls (75\%). This finding is statistically significant (7.82, df 2, p 0.02). About 33\% said that it was a physiological process in women and the rest said they did not know why it occurs.

Regarding food items which were to be avoided during menses, curds is most commonly mentioned item followed by fruits (apples, papaya and grapes), hot spicy foods, potatoes, sweet corn and sweets. All the Muslim girls $(100 \%)$ had dietary restrictions during menses. $62.7 \%$ of the Hindu girls and $25 \%$ of the Christian girls had dietary taboos during periods. (Chi Sq 23.6, df 2, p 0.000007).

\section{DISCUSSION}

The participants of this study, coming to the selected degree college, all reside around Guntur city which is a medium sized city in AP state surrounded by many towns and villages. There are not many demographic differences between the girls other than religion and caste which also are in line with that of the national statistics. Coming to the knowledge exhibited by the girls concerning Menstruation, it is seen that the role of the mother in giving proper knowledge to her child before puberty is very important.

Fakhri M et al suggest that attitude towards menstruation is related to menstrual health. A good number of women who considered menstruation as a natural phenomenon exhibited excellent menstrual health. ${ }^{12}$ Sources of information about menstruation were mainly mothers, health care professionals at clinics, friends, elder sisters, other family members, books and magazines, mass media and other.

As seen in other studies, many of the girls reported severe to moderate dysmenorrhea. Ehsen I et al found that $52 \%$ of the girls they interviewed used analgesics for dysmenorrhea. ${ }^{13}$ Menstruation associated complaints which contributed to school absenteeism were mainly pain and heavy bleeding.

Absenteeism from college is not just due to the physical complaints. Sanitary facilities and waste management at schools, including the hygienic disposal of sanitary napkins and other protection alternatives, are often so poor that girls and female teachers prefer not to use these during their menstruation period. This often results in missed classes and prolonged absences. ${ }^{14}$ Research confirms that the onset of puberty leads to significant changes in school participation among girls. ${ }^{15}$

All activities surrounding menses such as the removal of used pads, washing and drying themselves followed by applying a new pad etc require privacy for the young girl. If the girl is using cloth, she would require space and privacy to wash and dry the cloths. Poorly washed and dried cloths can lead to ascending infections of the vagina and uterus.

Van Eijk AM et al in their Meta-analysis of previously done studies have shown that commercial pad use was more common among urban than rural girls, with use increasing over time. Inappropriate disposal was common. Approximately a third of girls changed their absorbents in school facilities. ${ }^{16}$

Most of the girls have used cloth at least once in their life and hence are not alien to the concept of using cloth and washing it. Menon KR et al suggest that many of the girls continue to use cloth at home and pad when outside. ${ }^{17}$ In a study done in West Bengal, by Yasmin et al it was seen that the respondents who used old washed cloth had problems while washing and drying them due to lack of privacy. Keeping the cloth in places away from prying eyes became a problem for them and for that they usually dried and stored in un-hygienic places. ${ }^{3}$

Singh SP et al found that the false belief that girls get cranky during periods as quite prevalent. Many also believed that blood loss during periods made them weak. ${ }^{18}$ In recent years India has witnessed a $30 \%$ rise in the incidence of PCOS in young adolescent girls due to changes in lifestyle. Overall incidence quoted in literature is $11 \%$ of reproductive age group women but in adolescents it may be as high as $50 \%$. In present study we found the prevalence of PCOS to be $16.4 \%$ in married women and $24 \%$ in unmarried women. ${ }^{19}$

\section{CONCLUSION}

Menstruation is a challenge faced by women of reproductive age group in India and it is necessary to address and study the knowledge, attitude and practices of menstruation. Most families with a girl child are anticipating the event of menarche anxiously but are ill prepared.

There is inadequate awareness among the girl children, families, schools and colleges. The study showed clearly that educating women about the essentials facts about menstruation is necessary to prevent anxiety, school absenteeism, taboos and non-participation in important social, educational and religious activities.

The common symptoms faced by the menstruating girls restrict daily activities. Majority of the girls are experiencing restricting symptoms. The associated symptoms of menstruation need to be addressed in schools and colleges and in their respective homes. Required medicines need to be made available both at home and at the educational institutions. Depending on the severity and persistence of the symptoms some of the girls need to be attended by a physician and at times a 
Gynaecologist. Some may also require laboratory evaluation if they experience menorrhagia. The symptoms may be prevented or decreased in severity with minimal intervention. Awareness of menstruation and good menstrual practices can relieve some of the restrictions imposed upon the girls to facilitate their education, careers and social life. Discussing the challenges faced by the girls during menstruation with family and friends and colleges can relieve anxiety and stress.

Health care personnel within the purview of the home can also contribute to imparting essential knowledge on menstruation as seen in a study done in Mangalore. Availability of adequate water, sanitary products, basic medicines and privacy at home and at the educational institutions can address the challenges.

\section{Recommendations}

Advocacy of menstrual awareness programmes in educational institutions in urban and rural areas by Gynecological societies and NGO s to complement the existing government programmes. Printing a brochure in local language on Menstruation (awareness, challenges symptoms and signs) and making available in institutions and rural areas. Ensuring availability of sanitary products, water, privacy and appropriate waste disposal in all public services and institutions. Annual awareness camps in schools and colleges and other related institutions facilitated by local Gynecologists with follow up as required.

\section{ACKNOWLEDGMENTS}

The authors are grateful to all the participants of the study and the college management for their cooperation.

Funding: No funding sources

Conflict of interest: None declared

Ethical approval: The study was approved by the Institutional Ethics Committee

\section{REFERENCES}

1. Rajagopal S, Mathur K, 'Breaking the silence around menstruation': experiences of adolescent girls in an urban setting in India, Gender Develop. 2017; 25(2):303-17,

2. Gopalakrishnan S. Breaking the Silence: World Menstrual Hygiene Day, India Water Portal, 2016 20:43. Available at: http://sanitation.indiawaterportal.org/english/node/46 76.

3. Yasmin S, Manna N, Mallik S, Ahmed A, Paria B. Menstrual hygiene among adolescent school students: An in-depth cross-sectional study in an urban community of West Bengal, India. IOSR J Dent Med Sci. 2013;5(6):22-6.
4. Chandra-Mouli V, Patel SV Mapping the knowledge and understanding of menarche, menstrual hygiene and menstrual health among adolescent girls in lowand middle-income countries, Reproduct Health, 2017;14(1):30

5. Scott L, Montgomery P, Steinfield L, Dolan C, Dopson S, Sanitary pad acceptability and sustainability study, Research Funded by Green Templeton College, University of Oxford, Publication Supported by the Skoll Centre for Social Entrepreneurs, 2013. Available at http://www.doublexeconomy.com/publicationsprojects-2/sanitary-care-and-girls-education/

6. Anand E, Singh J, Unisa S. Menstrual hygiene practices and its association with reproductive tract infections and abnormal vaginal discharge among women in India. Sexual Reproduct Health. 2015;6(4):249-54,

7. National Family Health Survey - 4 - 2015 -16, India Fact Sheet, International Institute for Population Sciences, Mumbai. Available at http://rchiips.org/NFHS/pdf/NFHS4/India.pdf

8. Garg S, Anand T. Menstruation related myths in India: strategies for combating it. J Family Med and Primary Care. 2015;4(2):184-6.

9. Muralidharan A, Patil H, Patnaik S. Unpacking the policy landscape for menstrual hygiene management: implications for school WASH programmes in India. Waterlines. 2015;34(1):79-91.

10. Lawan UM, Yusuf NW, Musa AB, Menstruation and Menstrual Hygiene amongst Adolescent School Girls in Kano, Northwestern Nigeria African J Reproduct Health. 2010;14(3):201-7.

11. Adika VO, Yabga J, Apiyanteide FA, Ologidi PW, Ekpo KE, Perception and behaviour on use of sanitary pads during menstruation among adolescent school girls in Bayelsa State, Nigeria. Adv Appl Sci Res,2011;2(6):9-15

12. Fakhri M, Hamzehgardeshi Z, Golchin NAH, Komili A, Promoting menstrual health among Persian adolescent girls from low socioeconomic backgrounds: a quasi-experimental study BMC Public Health 2012;12(1):193.

13. Esen I, Oğuz B, Serin HM, Menstrual Characteristics of Pubertal Girls: A Questionnaire-Based Study in Turkey, J Clin Res Pediatr Endocrinol. 2016; 8(2):192-6

14. Ten VT. Menstrual hygiene: a neglected condition for the achievement of several millennium development goals. Europe External Policy Advisors. 2007:1-22.

15. Stefanie Kaiser. Menstrual Hygiene Management. 2008. [Last accessed on 2014 Aug 09]. Available from: https://www.sswm.info/humanitariancrises/camps/hygiene-promotion-communitymobilisation/hygiene-promotioncommunity/menstrual-hygiene-management.

16. van Eijk AM, Sivakairmi M, Thakkar MB, et al. Menstrual hygiene management among adolescent 
girls in India: a systematic review and meta analysis.BMJ Open 2016;6:e010290.

17. Menon KR, Vimal R, Suseela N, Case Study: Creating opportunities for women to be change makers in their community through addressing the silence around menstruation and related practices. Available at: https://kavyarmenon.wordpress.com/2015/09/15/case -study-addressing-the-silence-around-menstruationpaper-presented-at-the-international-womensconference-bridging-rural-and-global/

18. Singh SP, Singh M, Arora M, Sen P, Knowledge assessment regarding puberty \& menstruation among adolescent girls, Indian J. Prev. Soc. Med, 2006; 37(1 and 2):9-14.
19. Choudhary A, Jain S, Chaudhari P, Prevalence and symptomatology of polycystic ovarian syndrome in Indian women: is there a rising incidence?. Int $\mathbf{J}$ Reprod Contracept Obstet Gynecol. 2017;6(11):4971-5.

Cite this article as: Balla CP, Nallapu SSR.

Knowledge, perceptions and practices of menstrual hygiene among degree college students in Guntur city of Andhra Pradesh, India. Int J Reprod Contracept Obstet Gynecol 2018;7:4109-15. 